\title{
A Numerical Investigation on the Hydraulic Fracturing Effect of Water Inrush during Tunnel Excavation
}

\author{
Quan Zhang $\mathbb{D}^{1,2,3}$ Bingxiang Huang $\mathbb{D}^{1},{ }^{1}$ Manchao He, ${ }^{3}$ and Shan Guo ${ }^{3}$ \\ ${ }^{1}$ State Key Laboratory of Coal Resources and Safe Mining, China University of Mining and Technology, Xuzhou 221116, China \\ ${ }^{2}$ School of Mines, China University of Mining and Technology, Xuzhou 221116, China \\ ${ }^{3}$ State Key Laboratory of Geomechanics \& Deep Underground Engineering, China University of Mining and Technology, \\ Beijing 100083, China
}

Correspondence should be addressed to Quan Zhang; zhangquan@cumt.edu.cn and Bingxiang Huang; huangbxcumt@outlook.com

Received 27 January 2020; Revised 25 October 2020; Accepted 9 November 2020; Published 9 December 2020

Academic Editor: Umberta Tinivella

Copyright (C) 2020 Quan Zhang et al. This is an open access article distributed under the Creative Commons Attribution License, which permits unrestricted use, distribution, and reproduction in any medium, provided the original work is properly cited.

\begin{abstract}
When a high-pressure water source is located near a tunnel under excavation, water inrush is commonly associated with a hydraulic fracturing effect. To study the hydraulic fracturing effect of water inrush (HFEWI), flow-rock failure process analysis $\left(\mathrm{F}-\mathrm{RFPA} \mathrm{A}^{2 \mathrm{D}}\right.$ ) was adopted to simulate the water inrush process. The simulated results indicated that a stress disturbance area formed in front of the excavation face and that a hydraulic fracture zone formed in front of the karst cavity. Similarly, stress concentrations formed in front of the excavation face and the karst cavity. The hydraulic fracturing effect was characterized by stress concentration, and the local hydraulic crack propagation was the result of stress concentration. In addition, a pore pressure gradient formed in the crackfree area of the surrounding rock, and the occurrence of hydraulic cracking was the root cause of the significant change in water flow. When the hydraulic cracks initially formed and expanded, the zone of crack activity was large. As the cracks continued to expand, the range of activity decreased and finally concentrated directly in front of the excavation face. Additionally, the shapes of the water inrush channel obtained by the experimentation and numerical simulation were basically the same: semielliptical. During the evolution of hydraulic crack initiation, expansion, and penetration, the bottom of the excavated borehole was initially dry and then experienced seepage and water inrush. Finally, the minimum safe thickness of the rock wall was calculated to provide a safety guideline for this type of water inrush.
\end{abstract}

\section{Introduction}

Water inrush disasters occur frequently during the mining of mineral resources and the excavation of traffic tunnels and hydropower stations [1-4]. With the reduction in shallow mineral resources [5], mining depths have been increasing year over year [6]; thus, the water pressures expected at these mining depths have gradually increased as well. When the mining depth is more than $1000 \mathrm{~m}$, karst water pressure can exceed $7 \mathrm{MPa}$ [7]. For example, the water pressure in the Xinyi Mine, Yi'an Mine, and Mengjin Mine of the Yimei Group is $7.5 \mathrm{MPa}$, and the water pressure of the Ordovician limestone confined water in the Shandong Xingcun Minefield can reach $13 \mathrm{MPa}$ [8]. The water pressure in deep tunnels is also high. For example, the maximum burial depth of the diversion tunnel of the Jinping II Hydropower Station is approximately $2525 \mathrm{~m}$, and the maximum water pressure exceeds $10 \mathrm{MPa}$ [9]. Therefore, when a rock mass excavation project becomes deep, the pressure of the pressurized water is high and hydraulic fracturing is prone to occur during the water inrush process [10].

Hydraulic fracturing is one of the core mechanisms of the water inrush process under high water pressure [11]. Water can continuously induce hydraulic fracturing at crack tips [12], so the rock failure mechanism [13] of the water inrush channel caused by hydraulic fracturing is different from that caused by solid stress [14]. The mechanical action of groundwater is induced by its hydrostatic pressure and hydrodynamic pressure, both of which can cause the hydraulic fracturing effect of water inrush (HFEWI) [15]. There are 


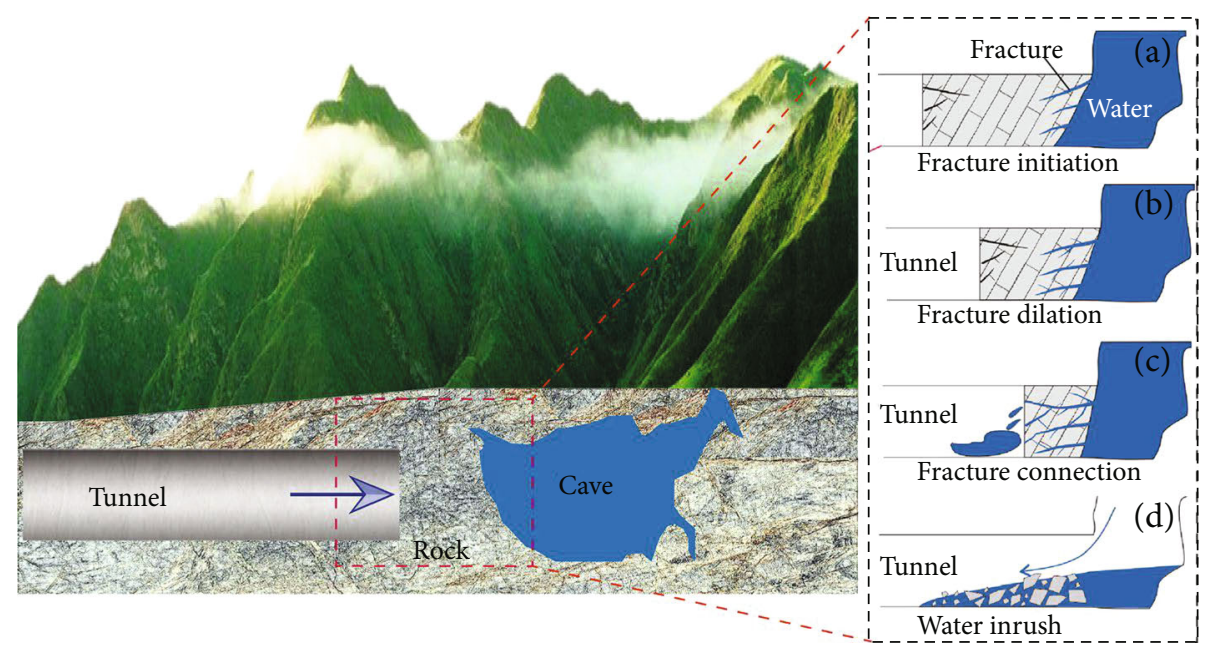

Figure 1: Water inrush process diagram. (a) Fracture initiation. (b) Fracture dilation. (c) Fracture network formation and leakage. (d) Water inrush [27].

two HFEWI types: pure splitting and stress splitting. The pure splitting type reflects hydraulic fracturing of a fractured rock mass, while the stress splitting reflects the hydraulic fracturing of an intact rock mass [16]. The HFEWI is associated with a high risk of fracturing, rapid flow rate, and high water flow pressure [17].

At present, the HFEWI has mainly been analyzed theoretically. From the perspective of fracture mechanics, the critical water pressure of the HFEWI from an unidentified fault in a coal floor was calculated [18]. The HFEWI occurred in the sidewall of a collapse column when the collapse column was far from the mining face or roadway, and the intrinsic cracks in the coal and rock mass were opened by the groundwater via hydraulic fracturing, which caused water inrush [19]. Additionally, the critical burst pressure of water inrush was derived for this case $[19,20]$. For the water inrush from a fractured rock mass, the formulas for calculating the critical water pressure of the HFEWI from a deep tunnel under the two failure modes of tensile-shear composite fracturing and compression-shear composite fracturing were deduced [21]. In addition, the critical water pressure for compressionshear failure was much less than that for tension-shear failure $[19,22]$, so the rock mass was more likely to undergo compression-shear failure. Moreover, crack propagation under the HFEWI presented intermittent characteristics [22]. To prevent water inrush in the case in which a highpressure water source is in front of the excavation face, the minimum safe thickness of the rock wall was calculated [23, 24]. However, most of these theoretical analyses focused on fractured rock masses. In addition, few numerical simulations have been carried out for the HFEWI. A functional relationship between the permeability coefficient and the damage variable was established and substituted into a numerical model to analyze the HFEWI from a mine floor [14]. The finite difference continuum code FLAC3D was used to analyze the HFEWI of a bottom collapse column. When the water pressure in a collapse column was greater than the minimum principal stress of the key layer of the bottom plate, the hydraulic fracturing phenomenon occurred in the water-blocking rock mass and formed a pipe surge, which led to mine water inrush [25]. By introducing a seepage-stress coupling model and employing ABAQUS to simulate the water inrush in deeply buried tunnels during excavation, it was considered that the high hydraulic gradient triggered the HFEWI [26]. Regarding the numerical simulation of the HFEWI, the floor water inrush during mining and the water inrush in a tunnel with highpressure water have been studied, but research on water inrush from karst cavities with high water pressures during tunnel or roadway excavation has rarely been carried out. The water pressure of the current water inrush experiments is still relatively low and has not reached the level of hydraulic fracturing. Therefore, there has been no experimental study of the HFEWI.

This is the first study to investigate the HFEWI when a karst cavity with a high water pressure is encountered in front of the face of a tunnel (Figure 1) with a true triaxial water inrush experiment. However, the experimental setup could not support observations of the whole process of crack initiation, expansion, and penetration through the test block, and only the final shape of the water inrush channel was inspected. The numerical simulation considered can visually reproduce the dynamic process of crack evolution under the disturbance action of the excavation and hydraulic splitting action of the high-pressure water. In addition, flow-rock failure process analysis (F-RFPA2D), which is based on the flow-stress-damage (FSD) coupling model, can describe the evolution of the stress field (maximum principal stress, minimum principal stress, and shear stress) and the seepage field (pore water pressure and volume of flow) during the process of water inrush channel formation. These models compensate for the deficiencies of the physical experiment. Therefore, F-RFPA2D was used to simulate the HFEWI of an intact rock mass. This work is conducive to the prevention and control of water inrush disasters, thereby increasing the safety of tunnel excavation. 


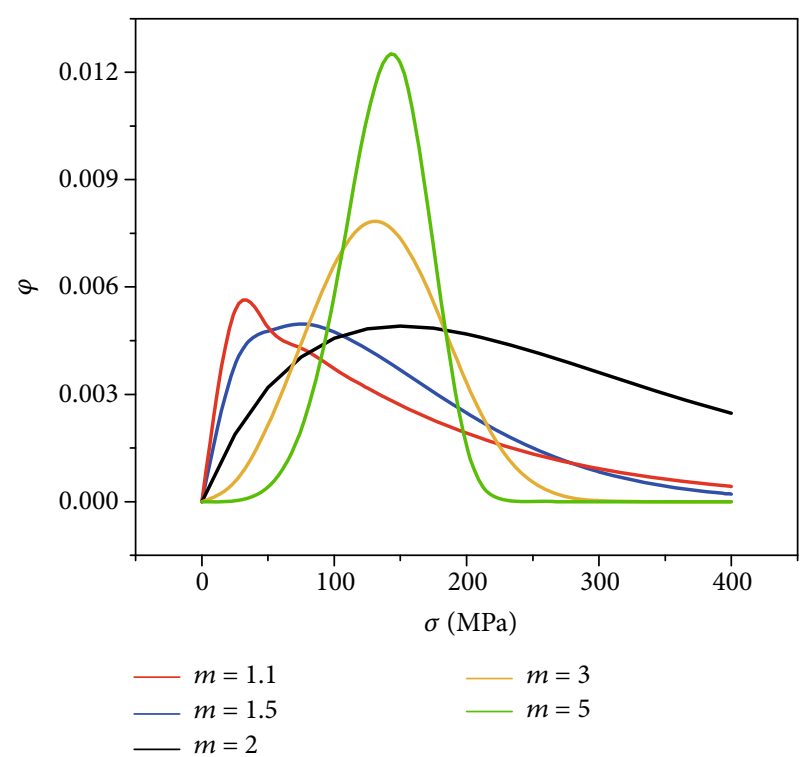

FIgURE 2: Strength distribution for five different heterogeneous coefficients.

\section{Methods}

2.1. Introduction of the Numerical Model. Considering the nonuniformity of a rock mass, F-RFPA2D transforms a complex macroscopic nonlinear problem into a simple mesoscopic linear problem that can accurately simulate the FSD coupling mechanism of rock during crack initiation and expansion. This software has been widely used in fluid-solid coupling studies [28], and its established numerical models have been verified many times [29-33].

Seepage-stress coupling follows classical Biot consolidation theory [34]. The main governing equations are as follows.

Equilibrium equation is as follows:

$$
\frac{\partial \sigma_{i j}}{\partial x_{i j}}+\rho X_{j}=0 \quad(i, j=1,2,3) .
$$

Strain-displacement equation is as follows:

$$
\begin{aligned}
& \varepsilon_{i j}=\frac{1}{2}\left(u_{i, j}+u_{j, i}\right), \\
& \varepsilon_{v}=\varepsilon_{11}+\varepsilon_{22}+\varepsilon_{33} .
\end{aligned}
$$

Constitutive equation is as follows:

$$
\sigma_{i j}^{\prime}=\sigma_{i j}-\alpha p \delta_{i j}=\lambda \delta_{i j} \varepsilon_{v}+2 G \varepsilon_{i j}
$$

Seepage equation is as follows:

$$
k \nabla^{2} p=\frac{1}{Q} \frac{\partial p}{\partial t}-\alpha \frac{\partial \varepsilon_{v}}{\partial t},
$$

where $\sigma_{i j}$ is the sum of the normal stress in the $i-j$ plane, $X_{j}$ is the body force in the $j$ th direction, $\rho$ is the rock density, $\varepsilon_{v}$

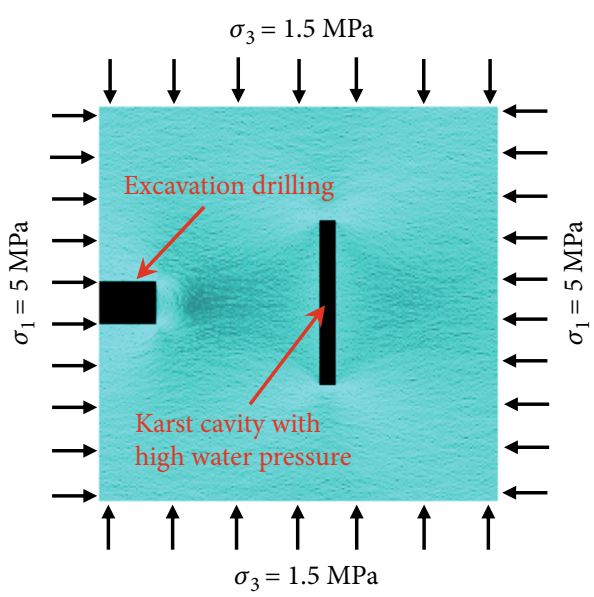

FIgURe 3: Numerical simulation model.

is the body strain ( $\varepsilon_{i j}$ is a positive strain), $\delta$ is the Kronecker delta, $G$ is the shear modulus, $\lambda$ is a Lamé constant, $Q$ is the Biot constant, and $\nabla^{2}$ is the Laplacian operator.

The mesostructural mechanical parameters of the material obey a Weibull distribution [35], which represents nonuniformity, that is,

$$
\varphi=\frac{m}{\sigma_{0}}\left(\frac{\sigma}{\sigma_{0}}\right)^{m-1} \exp \left[-\left(\frac{\sigma}{\sigma_{0}}\right)^{m}\right]
$$

where $\sigma$ is a certain parameter of the mesoscopic unit, $\sigma_{0}$ is the statistical average of the parameter of the mesoscopic unit, and $m$ is the heterogeneous coefficient. The strength distribution changes with five different heterogeneous coefficients, as shown in Figure 2. The elastic modulus follows the same distribution.

2.2. Numerical Simulation Scheme. The numerical simulation considered a plane strain model. As shown in Figure 3, the model size was $200 \times 200 \mathrm{~mm}^{2}$, which was divided into 200 $\times 200$ units. An $80 \times 7 \mathrm{~mm}^{2}$ karst cavity with a water pressure of $3 \mathrm{MPa}$ was represented in the model. The sample parameters [26] are shown in Table 1. The uniaxial compressive strength and uniaxial tensile strength of the rock were $20 \mathrm{MPa}$ and $2 \mathrm{MPa}$, respectively. The residual strength factor was 0.1 . The elastic modulus was $10000 \mathrm{MPa}$. The parameters such as elastic modulus and rock mass strength were randomly distributed according to a Weibull distribution and expressed by the homogeneity coefficient $m$. The greater $m$ was, the more uniform the parameter. The homogeneity coefficient was 4 . The permeability coefficient of the rock was $0.01 \mathrm{~m} / \mathrm{d}$, and the permeability coefficient jump rate was 20 . In addition, the pore water pressure coefficient was 0.1 . Poisson's ratio and internal friction angle were 0.25 and $30^{\circ}$, respectively. The vertical stress $\sigma_{1}$ was set to $5 \mathrm{MPa}$, and the horizontal stress $\sigma_{3}$ was $1.5 \mathrm{MPa}$. The water inrush process was triggered by an excavation disturbance. The diameter of the excavation was $20 \mathrm{~mm}$, and the number of excavation steps was set to 3 . In addition, the excavation distances were $30 \mathrm{~mm}, 25 \mathrm{~mm}$, and $20 \mathrm{~mm}$. 
TABLE 1: Numerical simulation parameters.

\begin{tabular}{lccc}
\hline Parameter & Value & Parameter & Value \\
\hline Compressive strength $\left(f_{\mathrm{c}}\right)$ & $20 \mathrm{MPa}$ & Homogenization $(\mathrm{m})$ & 4 \\
Tensile strength $\left(f_{t}\right)$ & $2 \mathrm{MPa}$ & Elastic modulus $\left(E_{0}\right)$ & Poisson's ratio $(v)$ \\
Self-weight $(\gamma)$ & $1.4 \times 10^{-6} \mathrm{~N} / \mathrm{mm}^{3}$ & Internal friction angle $(\varphi)$ & 0.25 \\
Residual strength factor $\left(f_{\mathrm{cr}} / f_{\mathrm{c}}=f_{t r} / f_{t}\right)$ & 0.1 & Water pressure $\left(\mathrm{p}_{\mathrm{c}}\right)$ & 30 \\
Permeability coefficient $\left(\mathrm{k}_{0}\right)$ & $0.01 \mathrm{~m} / \mathrm{d}$ & Coupling coefficient $(\beta)$ & $3 \mathrm{MPa}$ \\
Permeability coefficient jump rate $(\xi)$ & 20 & Excavation diameter $(d)$ & 0.01 \\
Pore water pressure coefficient $(\alpha)$ & 0.1 & & $20 \mathrm{~mm}$ \\
\hline
\end{tabular}
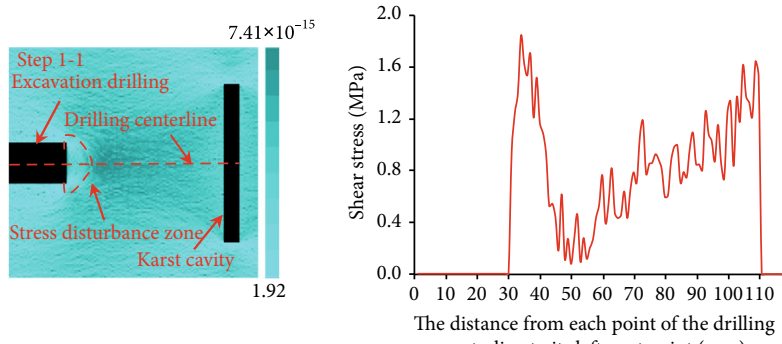

(a) Crack initiation stage
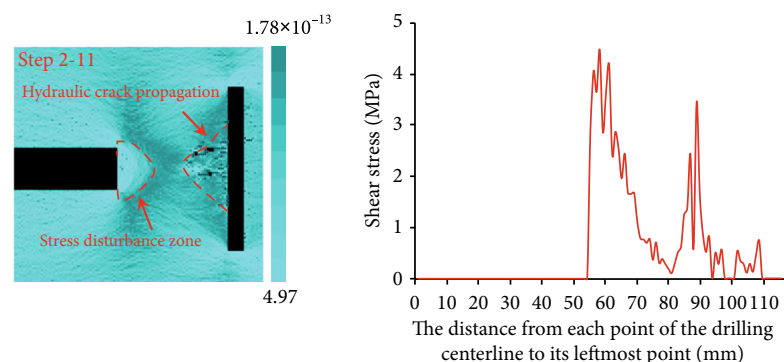

(c) Crack propagation stage (Step 2-11)
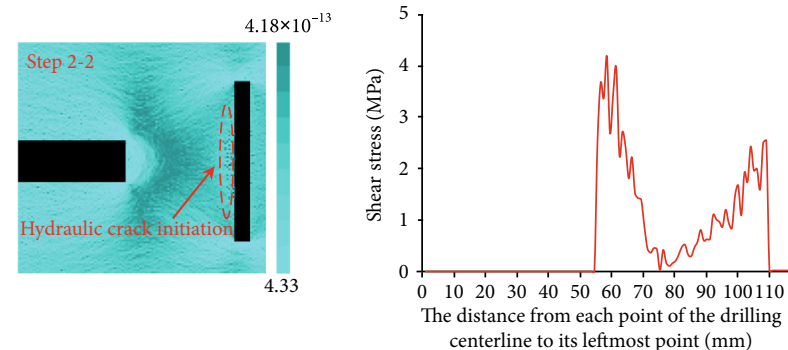

(b) Crack propagation stage (Step 2-2)

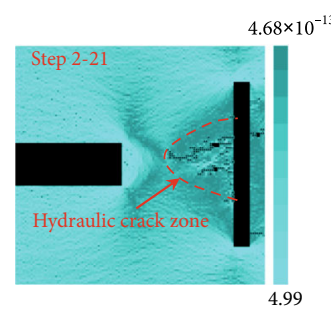

(d) Crack propagation stage (Step 2-21)

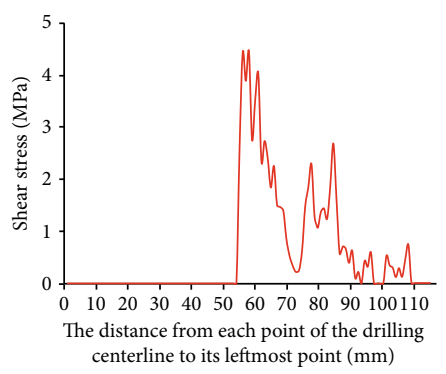

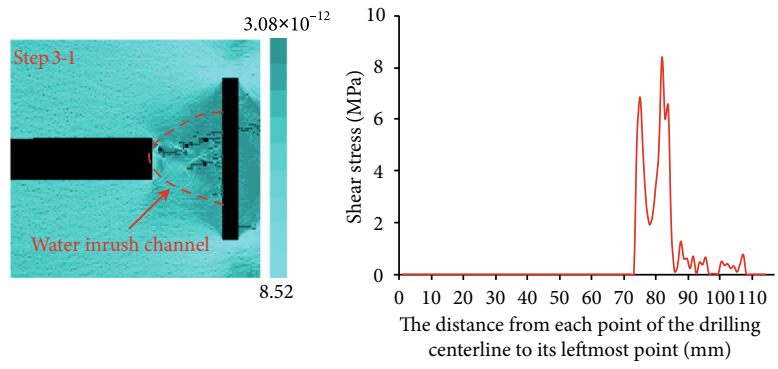

(e) Crack penetration stage

FIgUre 4: The shear stress evolution.

\section{Results}

3.1. The Evolution Pattern of the Stress Field. Excavation caused stress redistribution in the surrounding rock, and a stress disturbance zone was formed in front of the excavation face. A hydraulic fracture zone was created near the karst cavity. Stress concentrations formed in front of the excavation face and near the karst cavity. The drilling centerline (DCL) was selected to analyze the stress change process (Figure 4(a)). When the excavation face was $80 \mathrm{~mm}$ from the karst cavity, the maximum shear stress reached a peak of $1.84 \mathrm{MPa}$ (Figure $4(\mathrm{a})$ ) at $4 \mathrm{~mm}$ in front of the excavation face, the maximum value of the maximum principal stress was $4.48 \mathrm{MPa}$ at $7 \mathrm{~mm}$ in front of the excavation (Figure 5(a)), and the maximum value of the minimum principal stress was $3.10 \mathrm{MPa}$ at $23 \mathrm{~mm}$ in front of the excavation (Figure 6(a)). Furthermore, the shear stress and the minimum principal stress near the karst cavity also exhibited the phenomenon of stress concentration. When the distance between the excavation face and the karst cavity was $55 \mathrm{~mm}$, the stress disturbance zone in front of the excavation face became larger, and the peak values of the shear stress, 

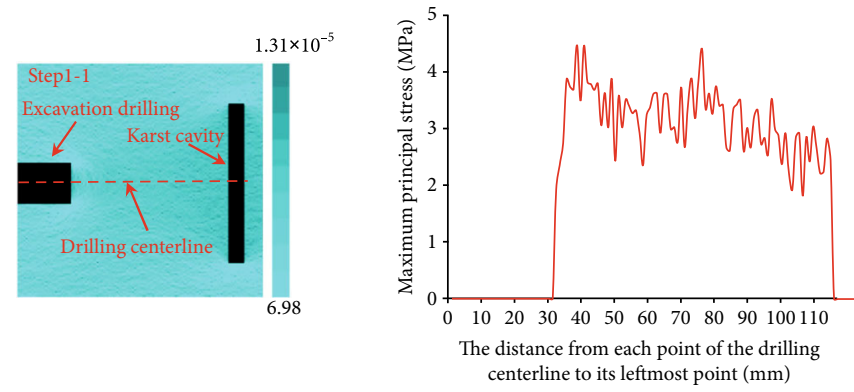

(a) Crack initiation stage

centerline to its leftmost point $(\mathrm{mm})$
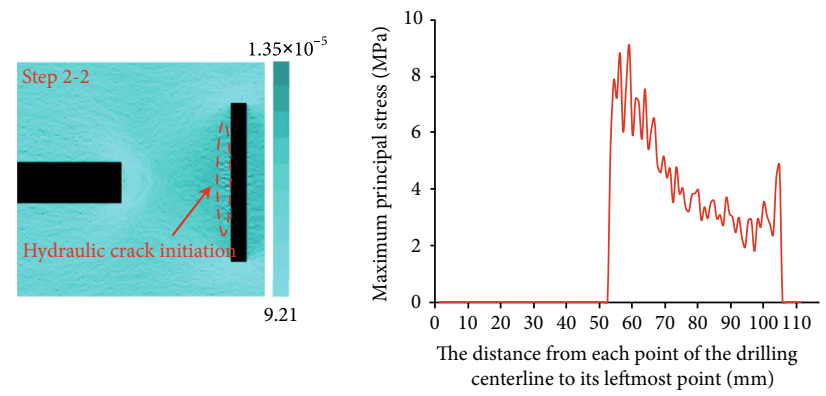

(b) Crack propagation stage (Step 2-2)
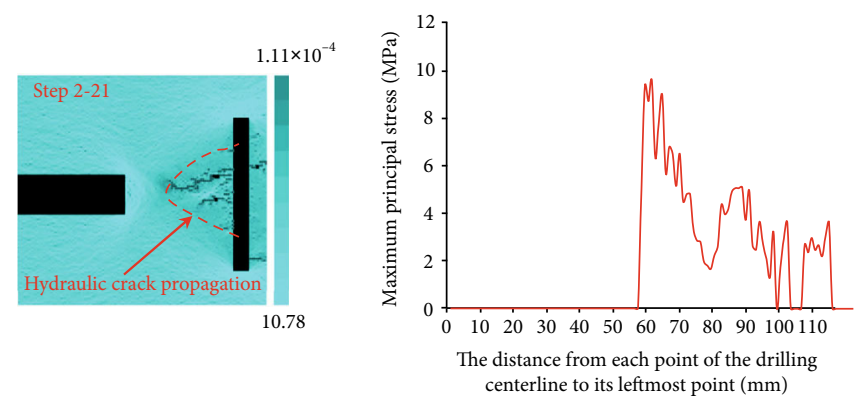

(d) Crack propagation stage (Step 2-21)

(c) Crack propagation stage (Step 2-11)


(e) Crack penetration stage

FIGURE 5: The maximum principal stress evolution.

maximum principal stress, and minimum principal stress along the DCL were $4.19 \mathrm{MPa}$ (Figure 4(b)), $9.08 \mathrm{MPa}$ (Figure 5(b)), and $4.43 \mathrm{MPa}$ (Figure 6(b)), respectively, which were greater than the corresponding results when the excavation face was $80 \mathrm{~mm}$ from the karst cavity. Moreover, as the distance between the excavation face and karst cavity decreased, the stress gradient in the surrounding rock increased. The peak shear stress, maximum principal stress, and minimum principal stress near the karst cavity were $2.52 \mathrm{MPa}, 4.86 \mathrm{MPa}$, and $-1.28 \mathrm{MPa}$, respectively, which were lower than the peak values of the stresses near the excavation face. When the excavation face was $35 \mathrm{~mm}$ from the karst cavity, the peak shear stress, maximum principal stress, and minimum principal stress along the DCL were $6.84 \mathrm{MPa}$ (Figure 4(e)), 17.62 $\mathrm{MPa}$ (Figure 5(e)), and $3.95 \mathrm{MPa}$ (Figure 6(e)), respectively. Additionally, the peak shear stress and maximum principal stress were higher than those and the peak minimum principal stress was slightly lower than that when the distance between the excavation face and the karst cavity was $55 \mathrm{~mm}$. However, the distance between the excavation face and the karst cavity was further decreased, so the stress gradient in the surrounding rock still increased.

There was no hydraulic crack initiation in the surrounding rock during the initial excavation, but energy was concentrated at the stress concentration. As the tunnel or roadway continued to be excavated, the rock at the stress concentration fractured, and hydraulic cracks were generated there. As the hydraulic cracks propagated forward, the position of the stress peak near the hydraulic fracture zone continuously moved forward (Figures 4(b)-4(d), Figures 5(b)-5(d), and Figures 6(b)-6(d)). This indicated that the stress peak near the karst cavity was located at the tip of the hydraulic crack. After the hydraulic cracks were generated, the water flowed into these cracks and created obvious stress concentrations and accumulated energy in the rock around the crack tips. When the energy at a crack tip exceeded the threshold required for hydraulic crack propagation, the crack expanded, releasing the energy and reducing the stress. Then, the water flowed into the extended crack tip and formed another stress concentration zone. Therefore, the hydraulic fracturing effect during the crack propagation stage is 

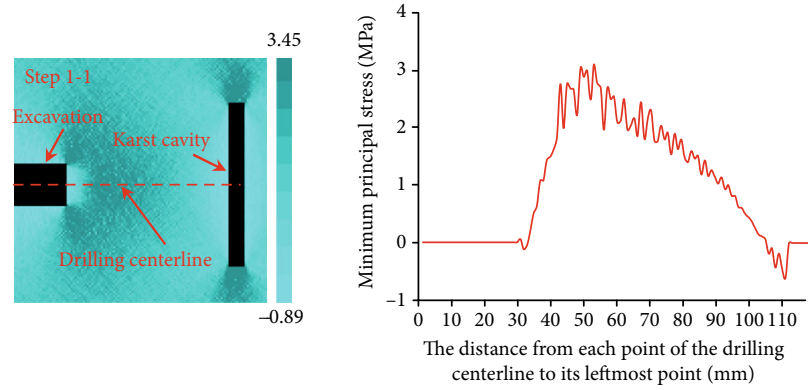

(a) Crack initiation stage
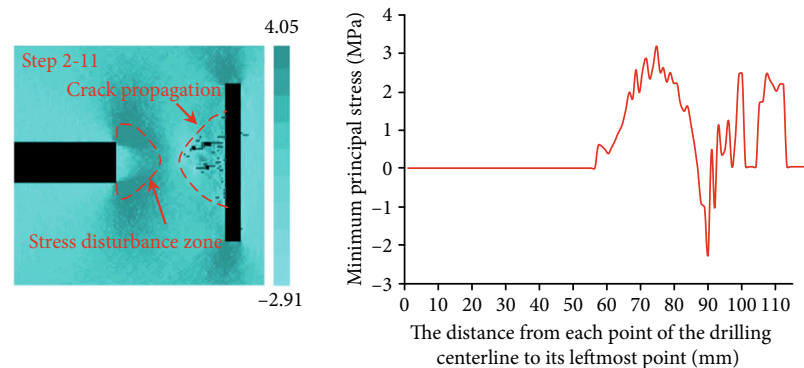

(c) Crack propagation stage (Step 2-11)
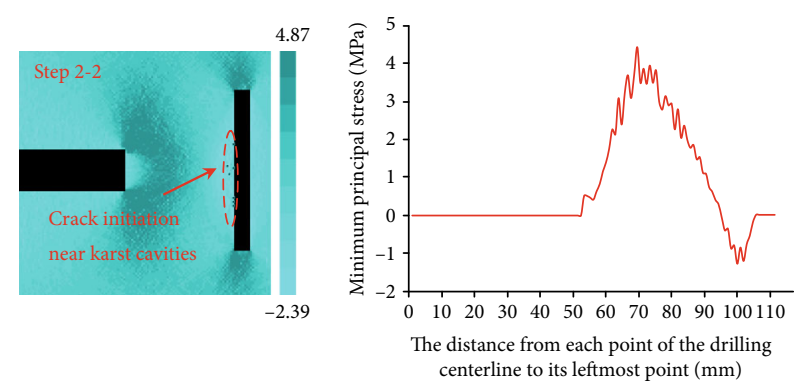

(b) Crack propagation stage (Step 2-2)
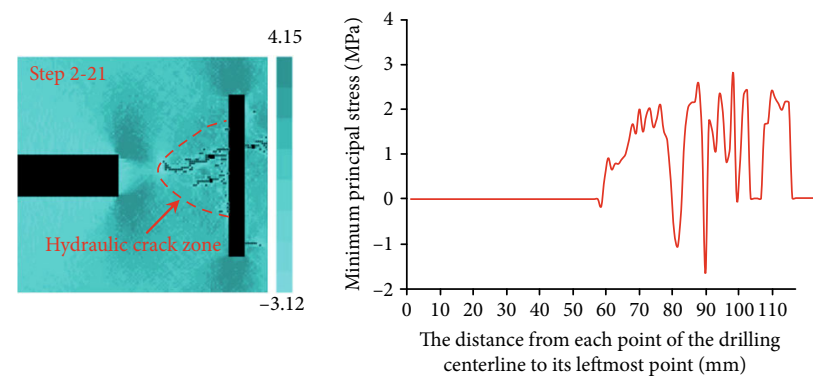

(d) Crack propagation stage (Step 2-21)
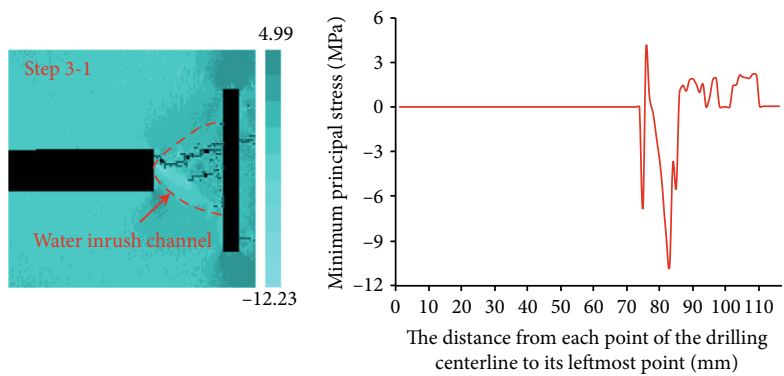

(e) Crack penetration stage

FIgURE 6: The minimum principal stress evolution.

characterized by stress concentration, and local crack propagation is the result of this stress concentration. Under the splitting action of water pressure, the entire rock mass does not reach the threshold of damage simultaneously; instead, the phenomenon of stress concentration appears locally. When the local concentrated energy exceeds the energy required for rock failure, hydraulic cracks propagate.

The similarity of the three types of stress evolution was that the three types of stress all formed stress concentrations in front of the excavation face and karst cavity, causing the surrounding rock to rupture and the water inrush channel to form. There were three differences between the three types of stress. First, the peak stress values of the shear stress and the minimum principal stress were smaller than the peak stress value of the maximum principal stress at the same excavation step. Second, the peak stress values of the shear stress and the maximum principal stress in front of the excavation face were all larger than those in front of the karst cavity during the whole excavation process. However, the peak stress value of the minimum principal stress in front of the excavation surface was greater than that in front of the karst cavity when the tunnel excavated to Step 1-1, Step 2-2, and Step 2-11. As the tunnel continued to be excavated to Step
2-21, the peak stress value of the minimum principal stress in front of the excavation face was less than that in front of the karst cavity. Third, the sign of stress represented the direction of stress in Figures 4-6. The shear stress and the maximum principal stress at different positions were always positive throughout the water inrush process, indicating that the direction of the stress did not change. However, the minimum principal stress changed from a positive value to a negative value at some locations, and from a negative value to a positive value at other locations, so the direction of the minimum principal stress direction changed.

3.2. The Evolution Pattern of the Seepage Field. The change in pore water pressure (Figure 7) showed that the pore water pressure was relatively high at the crack but low in the crack-free portion along the DCL. This was because the pressurized water flowed into the crack. When the distance from the excavation face to the karst cavity was $80 \mathrm{~mm}$ (Figure 7(a)), no crack was generated along the DCL, and the pore pressure reduced almost linearly from the edge of the karst cavity $(0.3 \mathrm{MPa})$ to the face of the excavation $(0 \mathrm{MPa})$, so a pore water pressure gradient formed in the surrounding rock. When the excavation face was 

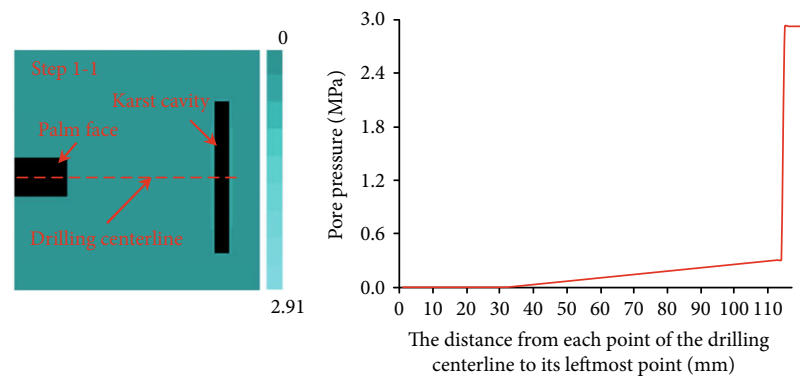

(a) Crack initiation stage
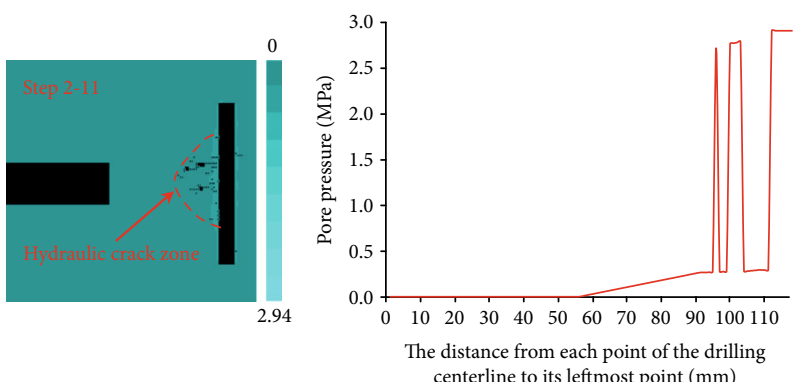

(c) Crack propagation stage (Step 2-11)
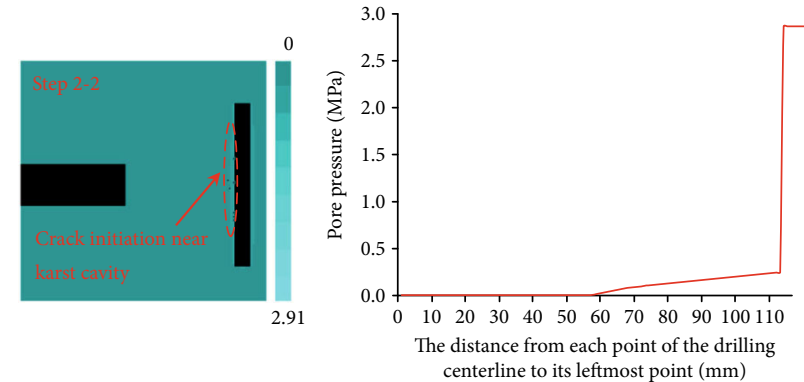

(b) Crack propagation stage (Step 2-2)
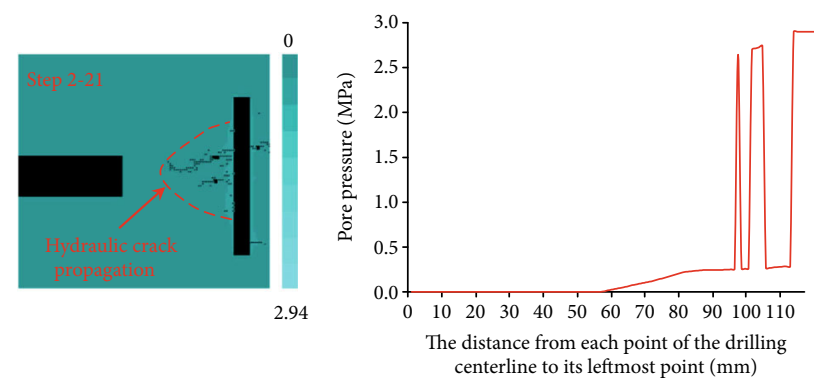

(d) Crack propagation stage (Step 2-21)
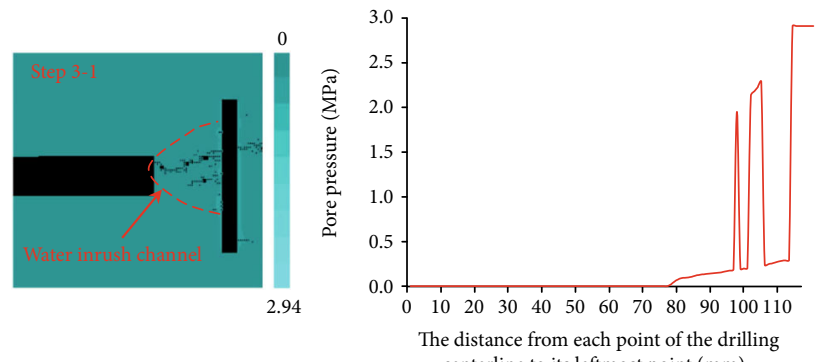

(e) Crack penetration stage

FIGURE 7: The pore water pressure evolution.

$55 \mathrm{~mm}$ (Figures 7(c) and 7(d)) and $35 \mathrm{~mm}$ (Figure 7(e)) from the karst cavity, the pore water pressure at the crack-free area gradually decreased from the karst cavity to the excavation face but exhibited a peak pressure at the crack.

The flow rate (Figure 8) reflects two patterns. One is that the horizontal flow was much greater than the vertical flow, indicating that the flow was mainly parallel to the direction of the DCL. Figure 8(a) shows that the flow in the horizontal direction of the surrounding rock along the DCL ranged from 322 to $449 \mathrm{~m}^{3} /(\mathrm{d} \cdot \mathrm{m})$, while that in the vertical direction ranged from 0.01 to $5.48 \mathrm{~m}^{3} /(\mathrm{d} \cdot \mathrm{m})$. Figures $8(\mathrm{~b})-8(\mathrm{e})$ show the same trends. The other rule is that the flow along the DCL was low before hydraulic cracks were generated, while the flow sharply increased after the cracks occurred. When there was no crack in the surrounding rock, the horizontal and vertical flow rates were low (Figure 8(a)). With the initiation (Figure 8(b)), expansion (Figures $8(\mathrm{c})$ and $8(\mathrm{~d})$ ), and penetration (Figure $8(\mathrm{e})$ ) of the hydraulic cracks, the horizontal and vertical flow rates dramatically increased. After formation of the water inrush channel, the horizontal flow along the DCL reached $53050 \mathrm{~m}^{3} /(\mathrm{d} \cdot \mathrm{m})$ (Figure $8(\mathrm{e})$ ), which was 118 times the maximum flow rate $\left(449 \mathrm{~m}^{3} /(\mathrm{d} \cdot \mathrm{m})\right)$ in the horizontal direction when no crack occurred (Figure 8(a)).
Additionally, the maximum vertical flow rate reached $17908 \mathrm{~m}^{3} /(\mathrm{d} \cdot \mathrm{m})$, which was much higher than the maximum vertical flow rate $\left(5.48 \mathrm{~m}^{3} /(\mathrm{d} \cdot \mathrm{m})\right)$ when no crack was generated (Figure 8(a)).

3.3. The Evolution Pattern of the Fracture Field. Under the joint effect of high-pressure water and excavation unloading, crack initiation, propagation, and penetration occurred in the surrounding rock, thus gradually forming a crack field. Acoustic emission analysis can record the process of damage and energy release inside a rock mass [36]. Therefore, it was used to describe the evolution process of the fracture field. The pattern of acoustic emissions under different excavation steps is shown in Figure 9. The sound waves in the acoustic emission diagram are represented by points and circles, and the positions of the points and circles illustrate the locations where the rock mass was destroyed.

In the crack initiation stage (Figure 9(a)), microcracks gradually developed near the karst cavity. When the microcracks were generated [37], the rupture energy was released in the form of elastic energy, and an acoustic emission signal appeared near the karst cavity. The crack originated mainly near the karst cavity directly in front of the excavation face. 


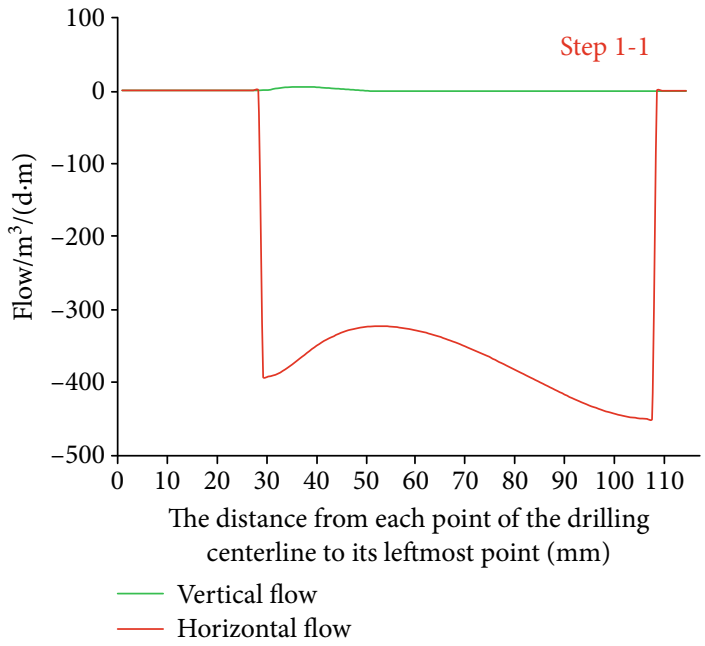

(a) Crack initiation stage

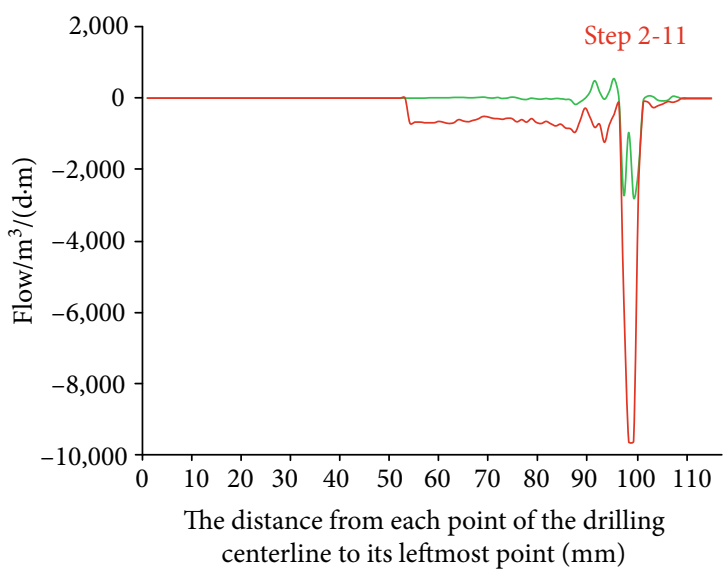

_ Vertical flow

Horizontal flow

(c) Crack propagation stage (Step 2-11)

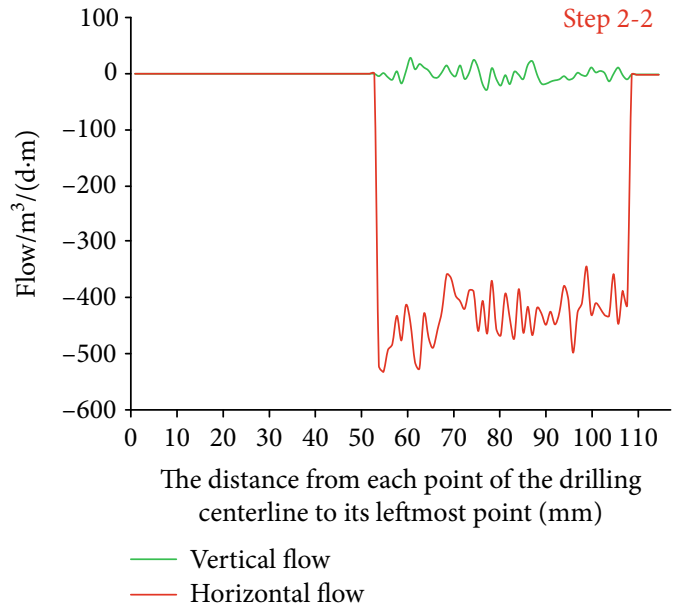

(b) Crack propagation stage (Step 2-2)

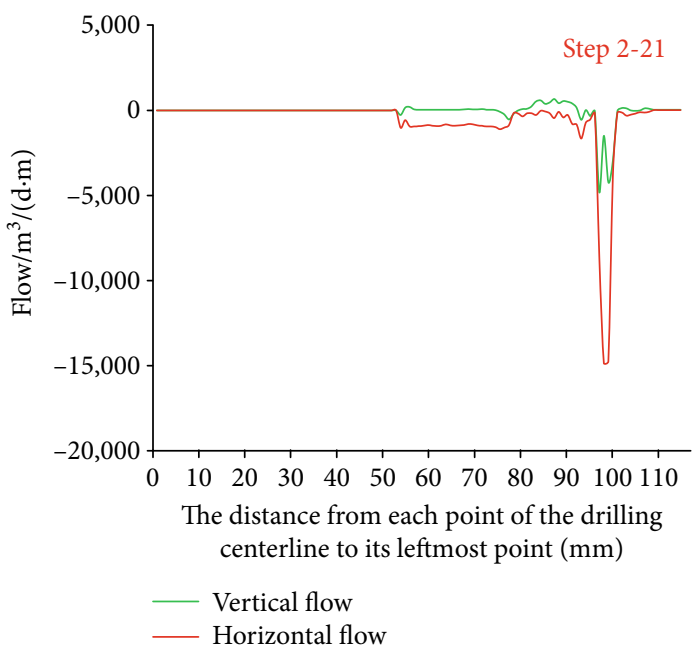

(d) Crack propagation stage (Step 2-21)
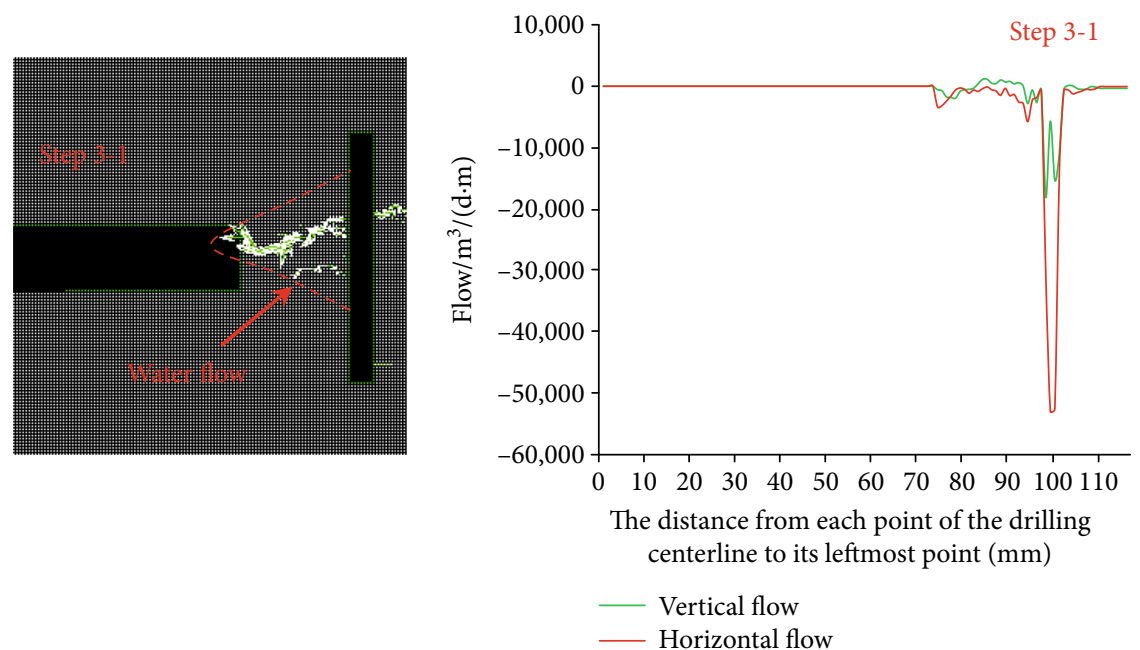

(e) Crack penetration stage

Figure 8: Flow evolution. 

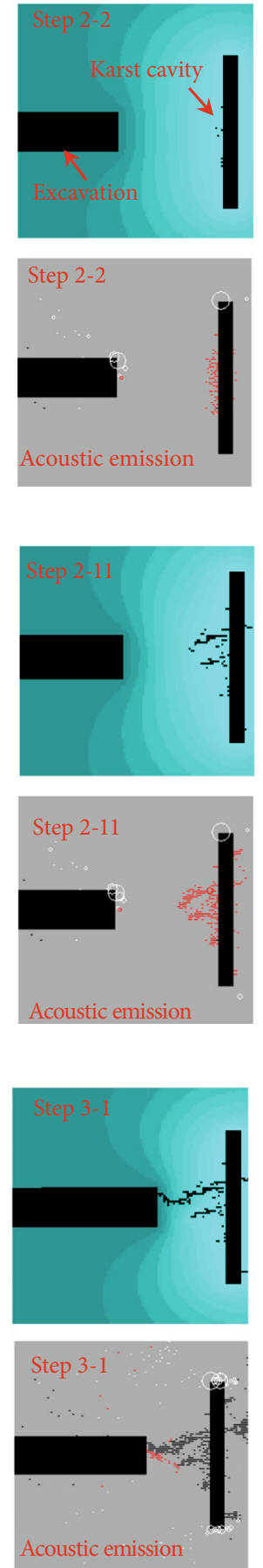
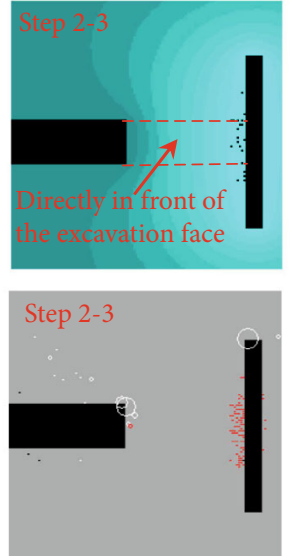

(a) Crack initiation stage


(b) Crack expansion stage
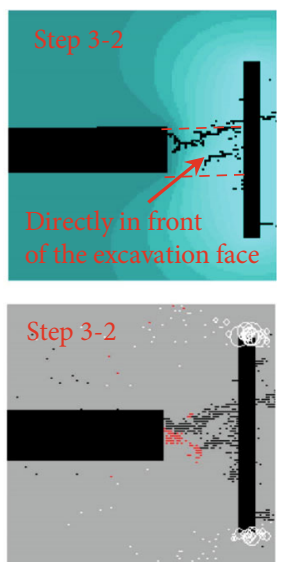

(c) Crack penetration stage
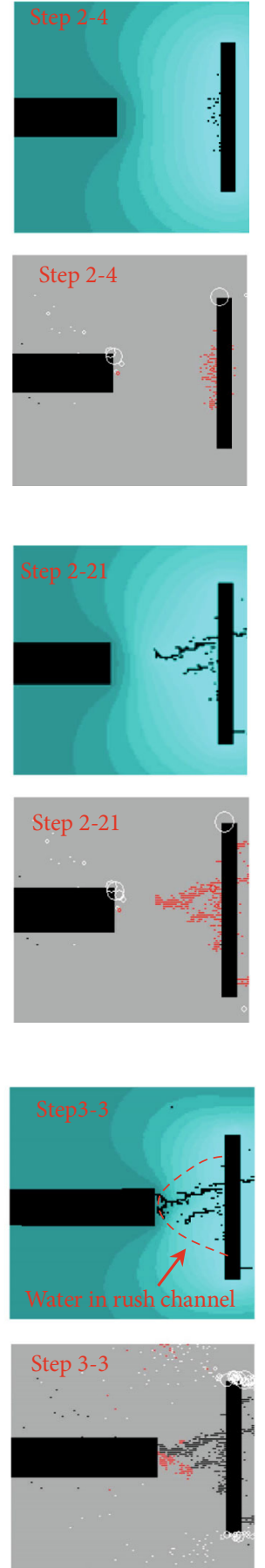

FIGURE 9: Crack field and acoustic emission evolution.

However, there was no crack initiation near the karst cavity far ahead of the excavation face.

During the crack propagation phase (Figure 9(b)), the surrounding rock experienced multiple progressive failures in a total of 26 small steps. When a crack initiated, the water pressure at the crack tip was 0 . After the water reached the crack tip, the water pressure increased continuously. When the energy at the tip of the crack reached that required for crack propagation, the energy accumulation ended, and the crack began to expand. Then, the crack evolution entered the period of crack propagation. This process was called the energy accumulation period. Before water inrush occurred, the crack propagation required passing through multiple energy accumulation periods, and the crack propagation range needed to exceed the minimum safe thickness of the rock wall, so the HFEWI exhibited hysteresis. Therefore, this characteristic can be used to ensure the safety of equipment and workers. 


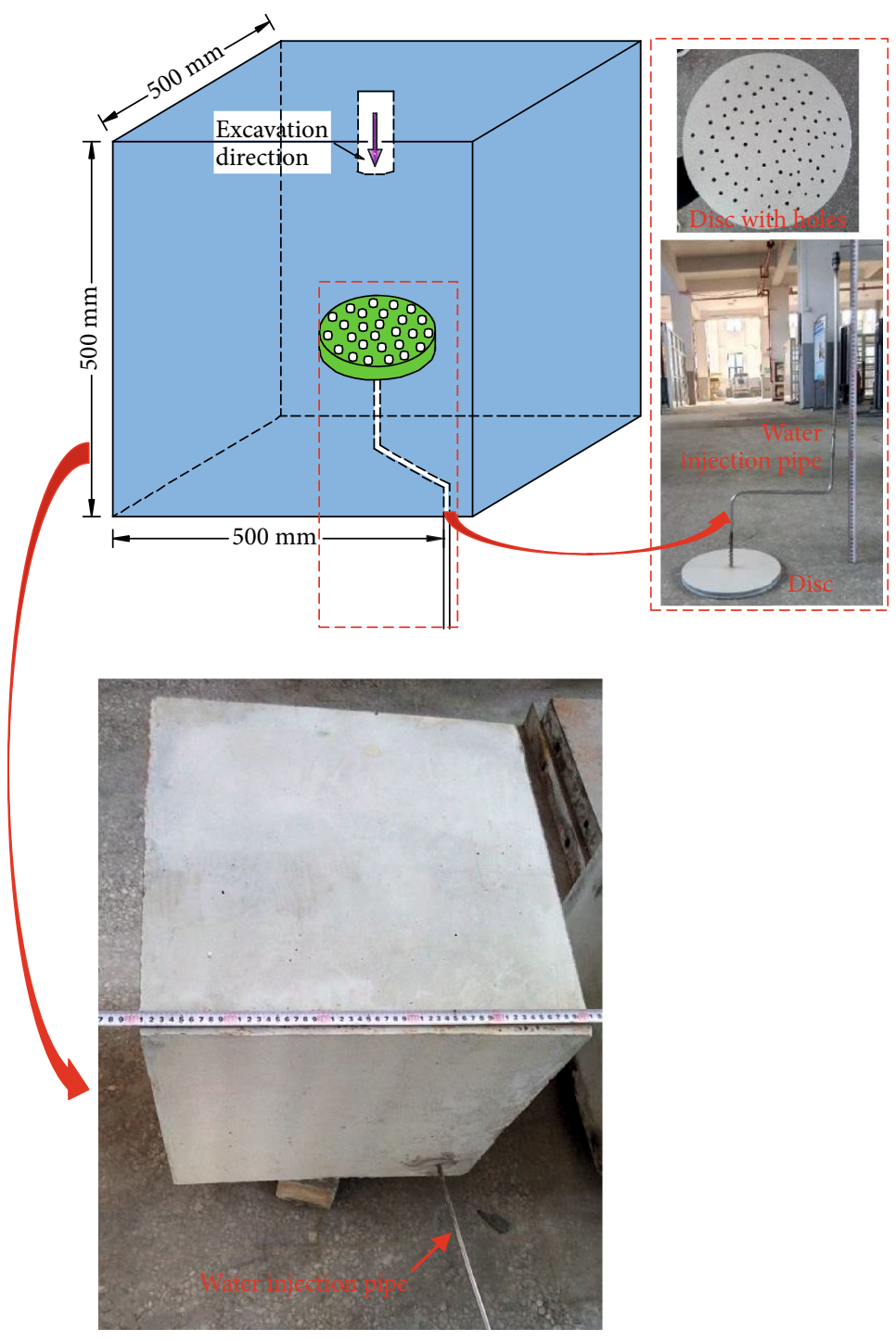

Figure 10: Test block.

In the crack penetration stage (Figure 9(c)), the cracks near the karst cavity directly in front of the excavation face extended to the excavation face. The cracks near the karst cavity far ahead of the excavation face generally did not extend far from the karst cavity; their extents were short and did not reach the excavation face. Since the water pressure is the same everywhere in the karst cavity, the stress disturbance directly in front of the excavation face between the excavation face and the karst cavity is greatest. The acoustic emission signal significantly increased during the crack penetration phase due to the sudden release of energy that had accumulated in the rock during an earlier stage. In addition, the acoustic emission signal was mainly concentrated in the water inrush channel and was more sparsely distributed in other locations.

\section{Discussion}

4.1. Comparison of Simulation and Experimental Results. A water inrush experiment under true triaxial stress was carried out. The size of the cement mortar sample was $500 \times 500 \times$ $500 \mathrm{~mm}^{3}$ (Figure 10). The sample contained a karst cavity with high-pressure water. The karst cavity was cylindrical, with a disc radius of $120 \mathrm{~mm}$ and a thickness of $18 \mathrm{~mm}$. The upper and lower circular plates were $4 \mathrm{~mm}$ thick. The edges between the upper and lower circular plates were supported by hard plastic and sealed with glue. Therefore, the aquifer was $10 \mathrm{~mm}$ high. A water injection pipe was connected behind the aquifer. The stress in the excavation direction of the test block was $6 \mathrm{MPa}$, and the stresses in the other two directions were $4 \mathrm{MPa}$ and $2 \mathrm{MPa}$. The test block was placed in the true triaxial water inrush experimental system and excavated from the top down (Figure 11). To observe the shape of the water inrush channel, red dye with a certain particle size was added to the water. There were five excavations in total. The first three excavation depths were $10 \mathrm{~cm}$, $4.5 \mathrm{~cm}$, and $5 \mathrm{~cm}$, and the water pressure during these three excavations was $6.5 \mathrm{MPa}$. Subsequently, the water pressure was increased to $7 \mathrm{MPa}$, and the fourth excavation was $2 \mathrm{~cm}$. Next, the water pressure was increased to $8 \mathrm{MPa}$, but 


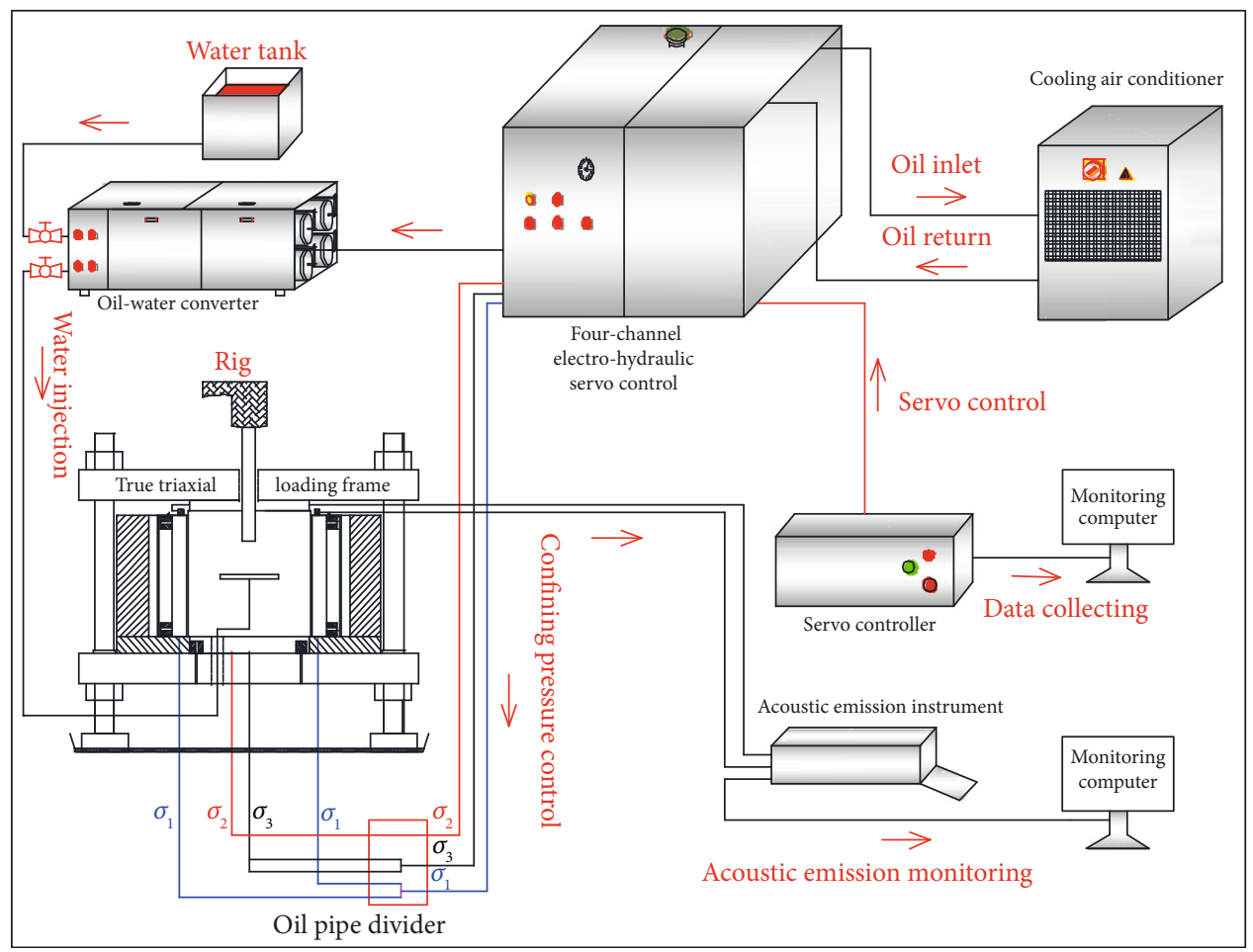

(a) Schematic diagram [38]

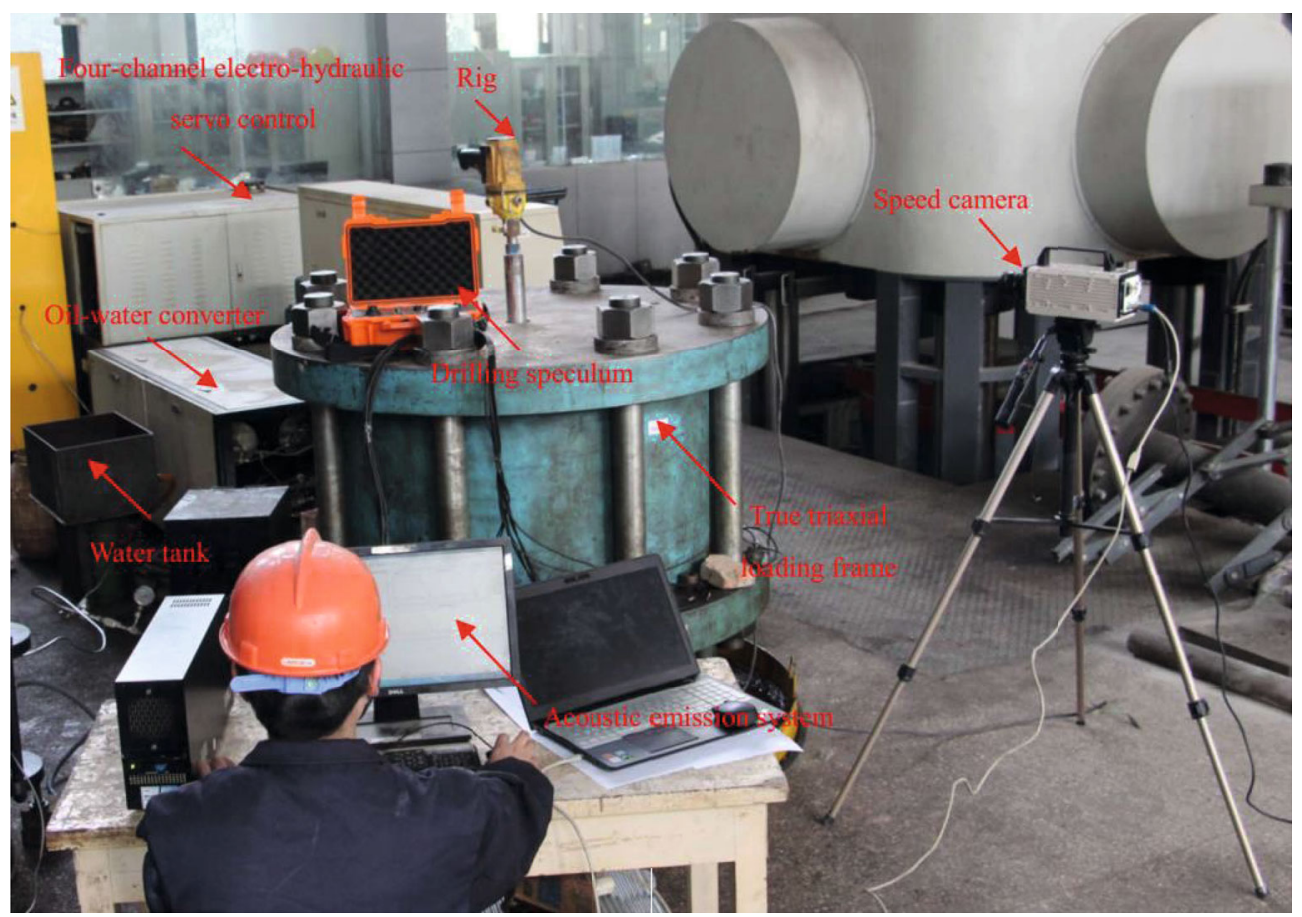

(b) Physical diagram

FIgURE 11: True triaxial water inrush experimental system.

no excavation occurred. Finally, the water pressure was increased to $8.5 \mathrm{MPa}$, and the fifth excavation was $1 \mathrm{~cm}$.

When the water pressure was $6.5 \mathrm{MPa}$, the bottom of the hole was initially dry (Figure $12(\mathrm{a})$ ) and then seeped (Figure 12(b)). However, the water did not turn red, since water could penetrate to the excavation surface, but the red pigment particles were large and could not penetrate there. This result indicated that the surrounding rock did not generate hydraulic cracks, only seepage. When the water pressure was $7 \mathrm{MPa}$, the water turned red (Figure 12(c)), indicating that a hydraulic fracturing effect had occurred and that a water inrush channel had formed. To analyze the 


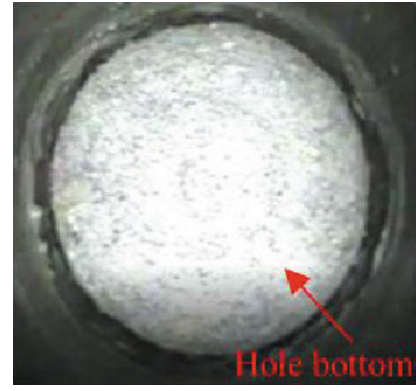

(a)



(b)

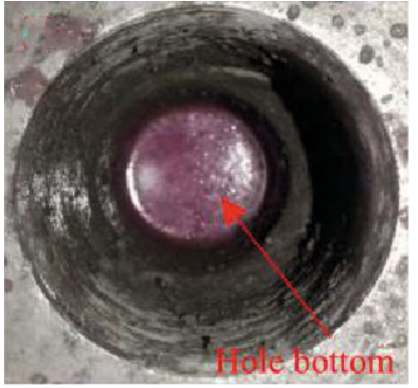

(c)

FIGURE 12: Water inrush process. (a) Crack initiation: dry hole bottom. (b) Crack propagation: leakage. (c) Crack penetration: water inrush (water turned red).

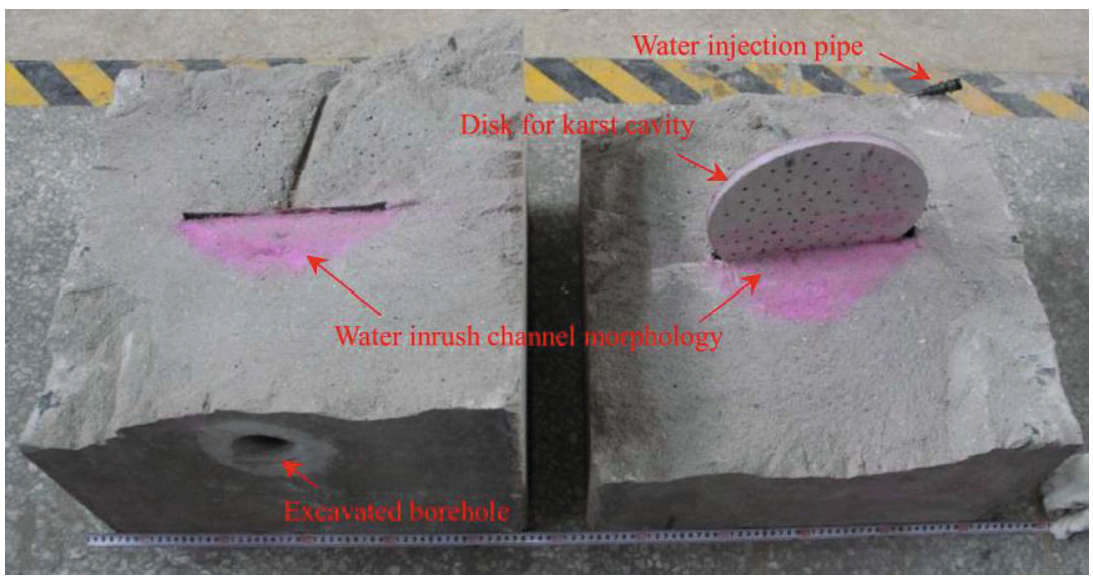

FIgURE 13: The shape of the water channel.

influence of the increase of water pressure on the hydraulic fracturing effect in the water inrush process, the water pressure was increased to $8 \mathrm{MPa}$ and $8.5 \mathrm{MPa}$. After the water pressure rose, the flow of water inrush became larger, and the amount of water inrush increased significantly.

After the experiment, the test block was opened. The red area in Figure 13 shows the shape of the water inrush channel. Numerous cracks were observed near the karst cavity, while fewer cracks were observed near the excavation face; those near the excavation face were concentrated directly in front of the excavation face. The simulation results (Figure 9) also show that when hydraulic cracks initiated and expanded, the hydraulic crack zone near the karst cavity was large. However, when the hydraulic cracks extended to the excavation face, the crack zone decreased, mainly located directly in front of the excavation borehole. Therefore, the morphologies of the water inrush channel obtained by the experiment and that obtained by the simulation are basically the same, and the shapes are all semielliptical.

Under FSD coupling, the hydraulic crack initiation and expansion of water inrush is the same as that of hydraulic fracturing. Therefore, under the action of high-pressure water, the water inrush during excavation has a hydraulic fracturing effect.

4.2. Minimum Safe Thickness of the Rock Wall. According to the simulation and test results, the minimum safe thickness

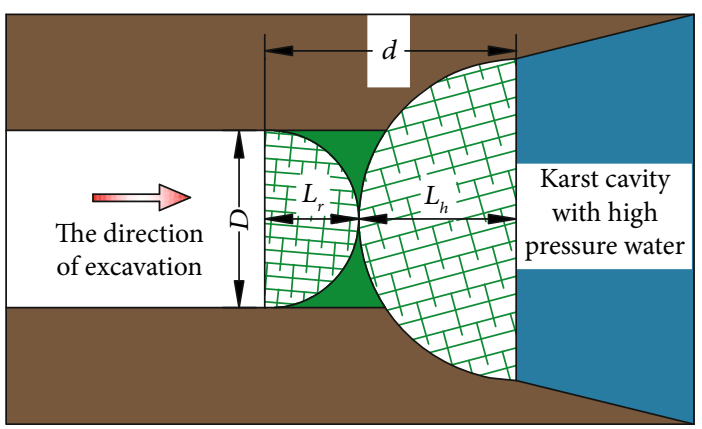

FIgURE 14: Schematic diagram of the minimum safe thickness for a rock wall.

of the rock wall is the sum of two distances (Figure 14): the maximum length $\left(L_{r}\right)$ of the stress disturbance zone in front of the excavation face and the maximum length $\left(L_{h}\right)$ of the hydraulic fracture zone in front of the karst cavity, that is,

$$
d=L_{r}+L_{h}
$$

According to the classical hydraulic fracturing crack extension model, the Khristianovich-Geertsma-de Klerk (KGD) model is as follows [39]: 


$$
P=\sigma_{\min }+0.242\left(\frac{2 G^{3} Q \mu}{(1-v)^{3} L_{h}^{2}}\right)^{1 / 4}
$$

where $P$ is the water pressure, $\sigma_{\text {min }}$ is the minimum in situ stress, $G$ is the shear modulus, $Q$ is the displacement of water, $\mu$ is the fluid viscosity, $v$ is Poisson's ratio of the rock, and $L$ is the crack length. Therefore, the maximum length of the hydraulic fracture zone is as follows:

$$
L_{h}=\left(\frac{2(0.242)^{4} G^{3} Q \mu}{\left(P-\sigma_{\min }\right)^{4}(1-v)^{3}}\right)^{1 / 2}
$$

The maximum length of the stress disturbance zone in front of the excavation face is the thickness of the loose ring [40], that is,

$$
L_{r}=a\left(\frac{(t)^{2 \sin \varphi /(1-\sin \varphi)}\left(p_{0}+m_{0} B_{0} \cot \varphi+c \cot \varphi\right)-\left(c-c^{*}+m_{0} B_{0}\right) \cot \varphi}{p_{a}+c^{*} \cot \varphi(1-\sin \varphi)}\right)^{(1-\sin \varphi) / 2 \sin \varphi}-a
$$

where $a$ is the radius of the roadway or tunnel, $\varphi$ is the internal friction angle of the surrounding rock, $p_{0}$ is the peak of the supporting pressure, $m_{0}$ is the slope of the stress-strain curve of the plastic zone, $c$ is the adhesion force of the surrounding rock, $c^{*}$ is the residual cohesive force of the surrounding rock, $p_{a}$ is the reaction force of the roadway support, $r$ is the distance from the center of the circular roadway, $R$ is the radius of the plastic zone, $t=r / R, E$ is the elastic modulus of the rock, and $B_{0}=(1 / 2 E)\left(p_{0} \sin \varphi+\cos \varphi\right)$.

Therefore, when water inrush exhibits a hydraulic fracturing effect, the minimum safe thickness of the rock wall is as follows:

$$
d=\left(\frac{2(0.242)^{4} G^{3} Q \mu}{\left(P-\sigma_{\min }\right)^{4}(1-v)^{3}}\right)^{1 / 2}+a\left(\frac{(t)^{2 \sin \varphi /(1-\sin \varphi)}\left(p_{0}+m_{0} B_{0} \cot \varphi+c \cot \varphi\right)-\left(c-c^{*}+m_{0} B_{0}\right) \cot \varphi}{p_{a}+c^{*} \cot \varphi(1-\sin \varphi)}\right)^{(1-\sin \varphi) / 2 \sin \varphi}-a
$$

\section{Conclusions}

It was previously believed that the mechanism of water inrush was solid stress and water seepage. A new mechanism of water inrush, which is the hydraulic fracturing effect, was proposed. A simulation method based on the FSD coupling model was used to study this mechanism. In addition, the true triaxial water inrush experiment method was adopted for the first time to investigate the HFEWI. Therefore, the following conclusions can be obtained.

The stress concentration caused by excavation and high water pressure makes the cracks in the surrounding rock form, expand, and penetrate, thus creating a water inrush channel. Moreover, this type of water inrush first undergoes three stages: seepage, hydraulic fracturing, and large-scale water inrush. Interestingly, the HFEWI exhibits hysteresis since the crack propagation process requires multiple energy accumulation periods. In addition, the shape of the water inrush channel is semielliptical. Finally, the minimum safety of the rock wall for fracturing water inrush is given quantitatively, which provides a theoretical basis for tunnel safety.

During the experiment, the pattern of the stress field and seepage field could not be studied. Therefore, pore water pressure sensors and skeleton stress sensors will be buried in the test blocks to investigate the patterns of solid stress and water pressure during water inrush. In addition, the HFEWI under high water pressure will need to be verified on site. This study focuses on the HFEWI in intact rock masses. Thus, experimental and simulation studies will be carried out on the HFEWI in fractured rock masses.

\section{Data Availability}

Data can be obtained by the email zhangquan@cumt.edu.cn.

\section{Conflicts of Interest}

The authors declare that they have no conflicts of interest.

\section{Acknowledgments}

The authors gratefully acknowledge the financial support from the National Key Research and Development Program of China (No. 2016YFC0600901), and the National Natural Science Foundation of China (No. 41941018).

\section{References}

[1] D. Ma, X. Cai, Z. Zhou, and X. Li, "Experimental investigation on hydraulic properties of granular sandstone and mudstone 
mixtures," Geofluids, vol. 2018, Article ID 9216578, 13 pages, 2018.

[2] J. L. Shao, F. Zhou, and W. Sun, "Evolution model of seepage characteristics in the process of water inrush in faults," Geofluids, vol. 2019, Article ID 4926768, 14 pages, 2019.

[3] J. Wang, Y. Zhang, Z. Qin, S. G. Song, and P. Lin, “Analysis method of water inrush for tunnels with damaged waterresisting rock mass based on finite element method-smooth particle hydrodynamics coupling," Computers and Geotechnics, vol. 126, article 103725, 2020.

[4] D. Ma, M. Rezania, H. S. Yu, and H. B. Bai, "Variations of hydraulic properties of granular sandstones during water inrush: effect of small particle migration," Engineering Geology, vol. 217, pp. 61-70, 2017.

[5] K. Peng, Z. P. Liu, Q. L. Zou, Q. H. Wu, and J. Q. Zhou, "Mechanical property of granite from different buried depths under uniaxial compression and dynamic impact: an energybased investigation," Powder Technology, vol. 362, pp. 729$744,2020$.

[6] Q. Wang, Z. H. Jiang, B. Jiang, H. K. Gao, Y. B. Huang, and P. Zhang, "Research on an automatic roadway formation method in deep mining areas by roof cutting with highstrength bolt-grouting," International Journal of Rock Mechanics and Mining Sciences, vol. 128, article 104264, 2020.

[7] M. C. He, H. P. Xie, S. P. Peng, and Y. D. Jiang, "Study on rock mechanics in deep mining engineering," Chinese Journal of Rock Mechanics and Engineering, vol. 24, pp. 2803-2812, 2005.

[8] D. Xu, Mechanism of fault reactivation-induced disasters during coal mining above high water-pressure confined aquifers, [Ph.D. thesis], China University of Mining and Technology, Geological Resources and Geological Engineering, 2012.

[9] L. P. Li, W. Lu, S. C. Li, Q. S. Zhang, Z. H. Xu, and S. S. Shi, "Research status and developing trend analysis of the water inrush mechanism for underground engineering construction," Journal of Shandong University (Engineering Science), vol. 40, pp. 104-112, 2010.

[10] V. N. Odintsev and N. A. Miletenko, "Water inrush in mines as a consequence of spontaneous hydrofracture," Journal of Mining Science, vol. 51, no. 3, pp. 423-434, 2015.

[11] J. Q. Guo and C. S. Qiao, "Study on water-inrush mechanism and safe thickness of rock wall of karst tunnel face," Journal of the China Railway Society, vol. 34, pp. 105-111, 2012.

[12] Y. L. Zhao, L. Y. Zhang, J. Liao, W. J. Wang, Q. Liu, and L. Tang, "Experimental study of fracture toughness and subcritical crack growth of three rocks under different environments," International Journal of Geomechanics, vol. 20, no. 8, article 04020128, 2020.

[13] Q. Zhang, M. C. He, J. Wang et al., "Instantaneous expansion with a single fracture: A new directional rock- breaking technology for roof cutting," International Journal of Rock Mechanics and Mining Sciences, vol. 132, article 104399, 2020.

[14] X. H. Xie, B. Y. Su, Y. F. Gao, and X. B. Duan, "Numerical study on water inrush above a confined aquifer in coal mining using hydro-fracturing," Chinese Journal of Rock Mechanics and Engineering, vol. 24, pp. 987-993, 2005.

[15] R. Q. Huang, X. N. Wang, and L. S. Chen, "Hydro splitting off analysis on underground water in deep lying tunnels and its effect on water gushing out," Chinese Journal of Rock Mechanics and Engineering, vol. 19, pp. 573-576, 2000.

[16] B. C. Liu, Z. K. Xiang, Y. S. Lin, C. M. Lu, and B. H. Zhang, "Karst tunnel water gushing mechanism in Jinping stage 2 hydropower station," Journal of Guilin University of Technology, vol. 28, pp. 484-488, 2008.

[17] X. Y. Li, D. L. Zhang, Q. Fang, and H. R. Song, "On water burst patterns in underwater tunnels," Modern Tunnelling Technology, vol. 52, pp. 24-31, 2015.

[18] Z. H. Chen, Z. P. Hu, H. Li, and Q. F. Chen, "Fracture mechanical model and criteria of insidious fault water inrush in coal mines," Journal of China University of Mining \& Technology, vol. 40, pp. 673-677, 2011.

[19] S. X. Yin and Q. Wu, "Generalized modes and academic criterions of water inrush from paleo-sinkholes," Journal of University of Science and Technology Beijing, vol. 28, pp. 812-817, 2006.

[20] Z.-H. Li, G. R. Feng, and C. Z. Zhai, "Study on "triangle" water-inrush mode of strong water-guide collapse column," Journal of Central South University, vol. 23, no. 9, pp. 24022409, 2016.

[21] Z. L. Li, H. C. Zhang, Q. W. Ren, and Y. H. Wang, "Analysis of hydraulic fracturing and calculation of critical internal water pressure of rock fracture," Rock and Soil Mechanics, vol. 26, pp. 1216-1220, 2005.

[22] X. Dong, H. Lu, H. X. Huang, Y. Hao, and Y. Xia, "Failure mode of the water-filled fractures under hydraulic pressure in karst tunnels," Open Geosciences, vol. 9, no. 1, pp. 186196, 2017.

[23] S. C. Li, Y. C. Yuan, L. P. Li, Z. H. Ye, Q. Q. Zhang, and T. Lei, "Water inrush mechanism and minimum safe thickness of rock wall of karst tunnel face under blast excavation," Chinese Journal of Geotechnical Engineering, vol. 37, pp. 313-320, 2015.

[24] Y. L. Zhao, S. L. Luo, Y. X. Wang, W. J. Wang, L. Y. Zhang, and W. Wan, "Numerical analysis of karst water inrush and a criterion for establishing the width of water-resistant rock pillars," Mine Water and the Environment, vol. 36, no. 4, pp. 508-519, 2017.

[25] S. X. Yin and Q. Wu, "Simulation and mechanism analysis of water inrush from karstic collapse columns in coal floor," Chinese Journal of Rock Mechanics and Engineering, vol. 23, pp. 2551-2556, 2004.

[26] J. X. Wang, Q. Li, W. X. Wu et al., "On water burst in deepburied tunnelling based on hydrofracturing method," Modern Tunnelling Technology, vol. 55, pp. 164-169, 2018.

[27] Z. Huang, W. Zeng, Y. Wu, S. J. Li, and J. Zhao, "Experimental investigation of fracture propagation and inrush characteristics in tunnel construction," Natural Hazards, vol. 97, no. 1, pp. 193-210, 2019.

[28] T. H. Yang, Study on infiltrate character and coupling analysis of seepage and stress in rock failure process, [Ph.D. thesis], Northeastern University, Engineering Mechanics, 2001.

[29] L. C. Li, Q. M. Meng, S. Y. Wang, G. Li, and C. A. Tang, "A numerical investigation of the hydraulic fracturing behaviour of conglomerate in glutenite formation," Acta Geotechnica, vol. 8, no. 6, pp. 597-618, 2013.

[30] S. Y. Wang, S. W. Sloan, S. G. Fityus, D. V. Griffiths, and C. A. Tang, "Numerical modeling of pore pressure influence on fracture evolution in brittle heterogeneous rocks," Rock Mechanics and Rock Engineering, vol. 46, no. 5, pp. 1165-1182, 2013.

[31] Y. Wang, X. Li, R. Q. Zhou, B. Zheng, B. Zhang, and Y. F. Wu, "Numerical evaluation of the effect of fracture network connectivity in naturally fractured shale based on FSD model," Science China-Earth Sciences, vol. 59, no. 3, pp. 626-639, 2016. 
[32] T. Xu, P. G. Ranjith, A. S. K. Au et al., "Numerical and experimental investigation of hydraulic fracturing in kaolin clay," Journal of Petroleum Science and Engineering, vol. 134, pp. 223-236, 2015.

[33] H. Q. Zhang, Y. N. He, C. A. Tang, B. Ahmad, and L. J. Han, "Application of an improved flow-stress-damage model to the criticality assessment of water inrush in a mine: a case study," Rock Mechanics and Rock Engineering, vol. 42, no. 6, pp. 911-930, 2009.

[34] M. A. Biot, "General theory of three-dimensional consolidation," Journal of Applied Physics, vol. 12, no. 2, pp. 155-164, 1941.

[35] W. Weibull, "A statistical distribution function of wide applicability," Journal of Applied Mechanics, vol. 18, pp. 293-297, 1951.

[36] X. Y. Shang and H. Tkalčić, "Point-source inversion of small and moderate earthquakes from $\mathrm{P}$-wave polarities and $\mathrm{P} / \mathrm{S}$ amplitude ratios within a hierarchical bayesian framework: implications for the geysers earthquakes," Journal of Geophysical Research: Solid Earth, vol. 125, no. 2, 2020.

[37] K. Peng, J. Q. Zhou, Q. L. Zou, Y. J. Zhang, and G. W. Tan, "Deformation characteristics and failure modes of sandstones under discontinuous multi-level cyclic loads," Powder Technology, vol. 373, pp. 599-613, 2020.

[38] Q. Zhang, Hydraulic fracturing effect of water inrush in excavation of roadways or tunnels, [M.S. thesis], China University of Mining and Technology, Mining Engineering, 2018.

[39] J. Geertsma and F. de Klerk, "A rapid method of predicting width and extent of hydraulically induced fractures," Journal of Petroleum Technology, vol. 21, pp. 1571-1581, 1969.

[40] M. X. Chu and J. G. Yan, "Definition and control of thickness of relaxed zone around mining gateway," Coal Science and Technology, vol. 31, pp. 53-55, 2003. 